\title{
PROPOSTA DE DESIGN COLABORATIVO USANDO A TÉCNICA DE CROCHÊ: novas aplicações para o artesanato do Espaço Mira Gabriel em Paragominas-PA
}

COLLABORATIVE DESIGN USING CROCHÉ'S TECHNIQUE: new applications for the crafts at Mira Gabriel in Paragominas-Pa

DIAS, Ruanderson Silva; Graduado em Design; Universidade do Estado do Pará

ruanderson_dias@hotmail.com

SOARES, João Roberto dos Santos; Mestre em Designer Universidade do Estado do Pará

sansoar.design@gmail.com

\section{Resumo}

O presente documento apresenta o resultado da ação de colaboração do design com o artesanato de crochê, efetuado através da interação do autor deste projeto (Dias) com o grupo de crocheteiras assistidas pelo Espaço Mira Gabriel, na cidade de Paragominas, Pará. O contato realizado contempla os preceitos do Design Social indicando campos novos de atuação profissional no município, que beneficie tanto os artesãos e artesãs quanto a sociedade local, valorizando aspectos de sua produção popular. $O$ projeto sequenciou-se por etapas inspiradas em outras produções do curso de design da UEPA, em suas relações com o artesanato, demonstrando a validade dessas ações em outros contextos. Como resultado, houve a concepção de uma coleção conceitual e primordial de sandálias inspiradas em borboletas da fauna amazônica, no intuito de referenciar o território amazônico e cumprir os requisitos de qualidade da ferramenta estrela de valores, e com isso, iluminar a produção artesanal no munícipio de Paragominas através do design.

Palavras Chave: Design; Artesanato; Crochê; Mira Gabriel.

\section{Abstract}

This document presents the result of the collaborative action in design with the crochet crafts, made through the interaction between the author and the group of artisans assisted by the Mira Gabriel space in the city of Paragominas, Pará. Social design precepts indicating new fields of professional activity in the region, which benefits both artisans and the local society, revalueting aspects of their popular production. The project was sequenced in stages inspired by other production of UEPA Design Course, in their relations with crafts, demonstrating the validity of these actions in other contexts. As a result, a conceptual and primordial collection of sandals inspired by butterflies of the Amazonian fauna, in order to refer to the Amazonian territory and to fulfill the quality requirements of the tool Star of Values, to illuminate by Design the artisan production in the field of Paragominas.

Keywords: Design; Craftwork; Crochet; Mira Gabriel. 


\section{Introdução}

Uma das sucessíveis demonstrações de sucesso do design social está na sua inserção no artesanato. A sensibilidade do designer na elaboração projetual combinada com a técnica artesã, consideram pontos importantes que estão associados ao social e em especial ao território geográfico onde se concebe a criação. Para Staudt em seu experimento com design social, para a valorização de produtos artesanais com enfoque no turismo local, "o design social visa um mercado mais solidário e sustentável, valorizando produtos, territórios e os indivíduos que ali interagem" (STAUDT, 2012, p. 1). Outros autores que viram no artesanato uma possibilidade de interagir o design, sugerem um desempenho mais aprofundado e igualitário, denominado de design colaborativo, defendido como o método eficaz para a realização de combinar o design a outras áreas.

O fato de o Brasil ser esse país que dispõe de uma mistura de etnias, costumes e manifestações culturais, propiciou a formação de habilidades manuais de grande contingente da população, nos mais variados locais, com técnicas passadas de pai para filho. Tais habilidades decorrem de um ambiente onde a "má distribuição de recursos e a sobrevivência humana dependem com frequência de soluções inusitadas" (CARDOSO, 2008, p. 250). O artesanato identifica-se com esse discurso, pois não deixa de ser uma manifestação cultural que se apresenta das mais variadas modalidades, formas e texturas, dando novos atributos a materiais disponíveis na natureza.

O artesanato que se utiliza de material e técnica endêmicos de uma região geram autenticidade e identidade para o lugar. Para Moura (2011, p. 32) de uma forma ou de outra, os profissionais do artesanato retratam em suas peças um estilo cultural, pelo uso dos materiais, forma e/ou linguagem. Como exemplo, cita-se o vaso de cerâmica marajoara, que pelo fato de ser dotado de uma técnica apreciada de 400 a 1400 anos d.C., com barro retirado do solo da própria região, consegue fazer referência tanto a llha de Marajó como a cultura do Estado do Pará, identificados pela estética apresentada no artefato.

O artesanato é entendido por esta pesquisa como o fazer artefatos através de técnicas manuais, utilizando matérias nativas ou não, com o incremento parcial de mecanismos industriais de produção em série no processo, tendo por objetivo a criação de peças úteis e artísticas. Dentre as principais manifestações do artesanato brasileiro, destaca-se a técnica de fazer renda, que é uma tradição trazida da Europa durante a colonização e se estabeleceu no país, em especial, na região litorânea. Outros tipos de renda possuem a nacionalidade brasileira, mesmo que algumas não tenham sido originadas no país, a relação aqui entra em contextos regionais e locais, ganhando novas aplicações e sentidos. Nas palavras de Zanella, Babinot e Pereira:

[...]Com as transformações sociais, modelos diferentes de renda foram criados, atendendo a demanda dos modos de produção capitalista existente na sociedade em que se inserem; em compensação, muitas rendas antigas deixaram de ser tecidas (ZANELLA, BALBINOT e PEREIRA, 2008, p. 172).

Porém uma renda que permanece, é a executada com a técnica do crochê, que se baseia na utilização de uma agulha específica como ferramenta, provida de um gancho na extremidade e que elabora um conjunto de pontos. Este último se consiste em nós e arremates feitos com a linha de barbante, podendo ser de lã ou de outro material, acarretando numa malha (REIS, 2016). Passivo de uma infinidade de aplicações, o crochê é adotado tradicionalmente para a confecção 
de tapetes, como também em adereços, agasalhos, objetos de decoração e etc.

Em Paragominas, no bairro Jaderlândia, localizado nos limites do perímetro urbano, o crochê é utilizado como forma de desenvolvimento, através dos trabalhos desenvolvidos no Espaço Mira Gabriel. Implantado pela vereadora Denise Gabriel, trata-se de uma organização filantrópica que visa promover cursos, com foco a atender mulheres que almejam aprender e exercer uma alternativa de renda para a família. Sobre os cursos levados à comunidade pela entidade, estão: crochê, prática de pintura, panificação, método de compostagem e agricultura família.

Atualmente o Espaço Mira Gabriel vem apresentando uma aplicação única do crochê. As peças de crochê desenvolvidas atualmente pelas assistidas possui concorrência com outros artesãos que elaboram a mesma categoria de produtos, ocasionando pouca atratividade para comercialização. Por essa realidade, a busca por novas formas de produzir e de aplicar o crochê, respeitando o conhecimento artesanal e combinando-o com o design é o problema a ser solucionado por esse projeto. Nesse sentido, a proposta conversa com as ideias de Moraes:

\begin{abstract}
A proposta de um novo produto, de forma consciente ou não, é fruto da interação dos atores envolvidos na concepção dos artefatos com a realidade sociocultural circundante. Isso se vê presente de maneira mais clara e definida quando nos voltamos para a produção artesanal popular. $\mathrm{O}$ artesanato, na verdade, é o resultado do convívio do homem com a sua cultura autóctone, suas tradições, suas crendices e religiosidades transformadas, por sua vez, em cultura material espontânea e popular (DE MORAES, 2010, p. 70).
\end{abstract}

O objetivo deste trabalho consiste em solucionar este problema através da elaboração de um projeto colaborativo de proposta conceitual com a técnica de crochê desempenhada no Espaço Mira Gabriel em Paragominas. Partindo primeiramente, do ato de descrever e analisar por meio da revisão de informações relevantes sobre as áreas envolvidas no projeto. Seguido pelo desenvolvimento de ferramentas da criatividade para o conceito do produto. Conduzindo para o objetivo final de conceber um demonstrativo de eficácia da colaboração do design com o artesanato através de uma minicoleção conceitual confeccionada no local.

O projeto pode ser enxergado em seu primeiro plano, como um objeto de contribuição para a aproximação do design com o artesanato na realidade local. Almeja ainda, esclarecer as benevolências da atividade de design como uma alavanca de valor para o artesanato. 0 mesmo serve de exemplo e incentivo, para que profissionais da área estendam seus conhecimentos para o serviço voluntário e social, contribuindo com soluções e inovações em provimento às entidades filantrópicas, que visam a melhoria de vida das comunidades menos favorecidas. O histórico de mudanças sociais realizadas em longo prazo por intermédio do Espaço Mira Gabriel e a sua significância para a comunidade do bairro Jarderlândia, sensibilizou o autor desse projeto em desenvolver uma proposta de colaboração conceitual com as crocheteiras do Mira Gabriel para servir de experimento nas tentativas de intervir o design em provisão à comunidade de baixa renda.

\title{
2 Design Social e Participativo
}

As bases ideológicas, as influências tanto de consumo, quanto de passado, sendo um movimento contínuo, não se anexam com o isolamento da profissão de design. Se o design não se relaciona com outras áreas, com novos conhecimentos, se o designer não interpreta o contexto 
social a sua volta e não busca inserir-se, onde podemos encontrar então a sua utilidade ou relevância social atuante? Para landim, não existe outra frase que melhor sirva como motor para os agentes do design, que o proverbio "pense globalmente, aja localmente" (LANDIM, 2010, p. 34). A esse tal lema, este presente projeto buscou se encaixar, pois, comprometeu-se em adentrar a causa local, adquirindo relevância ao grupo social em que se insere.

O design pós-moderno está mais próximo do povo do que o povo quer: está preparado para atender as suas necessidades legítimas sem moralizar sobre quais deveriam ser estas necessidades. Está, portanto, mais profundamente enraizado na sociedade do que a escola moderna (POYNOR, 2010, p. 19)

Para Riccetti, Martins e Ogasawara (2016) O design social como sendo uma categoria do sistema design, pode efetuar ações que nortearão o caminho a ser seguido pelas próximas gerações de designers, fazendo por essa atitude, consonância à especulação de Cardoso:

Costuma-se dizer que das crises nascem oportunidades e não resta dúvida de que a total falta de certeza do momento histórico presente oferece uma grande oportunidade para que os designers apresentem projetos de futuro e lancem novas bases para o exercício da profissão no século 21. (CARDOSO, 2008, p. 236)

Essa missão, indicada por Cardoso, familiariza-se ao propósito do Design Social. Onde, de acordo com Paula Dib, a ganhadora do prêmio Top XXI Mercado Design ${ }^{1}$, fala em entrevista:

[...] Design Social é aquele que deixa o contexto chegar antes de você chegar no contexto. Isso parece confuso, mas.... É um pouco isso, o designer pode acabar sendo muito intervencionista. Quando você fala em Design Social, você não está partindo do princípio de que você é o ativador daquilo, mas está ativando um sistema para participar desse processo. Esse sistema pode ser composto de pessoas, culturas, tempos.... É bem sutil mesmo a quantidade de coisas que se abarcam nesse social sabe? É um universo de sutileza que você convida a participar do processo para que ele de fato seja um processo social. (DIB/SEBRAE, 2015)

Ao considerarmos os desafios contemporâneos para o design, inserido nesse cenário dinâmico, em constante mutação e sortido de complexidades, o domínio técnico e linear, atravessa o terreno do intangível como característica de um produto (DE MORAES, 2010). Conforme Landim (2010, p. 119), "essa nova realidade exige também dos designers a consideração do tríplice aspecto: design, cultura e território. [...] exige, que seja observada a causa social". Moraes (2010, p. 11), compreende que, "tudo isso faz com que o design interaja, de forma, 'transversal e atravessável', com disciplinas cada vez menos objetivas e exatas, passando então a confluir com outras que compõem o âmbito do comportamento humano". Conforme o que o site Designers Brasileiros disponibiliza, por Luis Felipi Amorim, em seu artigo "Design (para o) Social":

A proposta do design social é humanizar a atividade projetual, buscando diagnosticar os pontos de partida e a perspectiva de chegada associando sonhos, necessidades, habilidades, recursos locais e a conexão entre pessoas, valorizando não somente o resultado, mas integrando e aprimorando o processo em que se realiza" (AMORIM, 2017).

Considerando tanto as falas de Dib quanto de Amorim, ao dirigirmos as interações do Design Social em processos produtivos artesanais, as recomendações de Mascêne passam a ser

\footnotetext{
${ }^{1}$ De acordo o site Design Brasil, esse prêmio consiste em reconhecer os designers e as empresas do setor, contribuindo ao fortalecimento e visibilidade do design nacional. Disponível em: <www.designbrasil.org.br/agenda/top-xxi-premio-design-brasil/> Acesso: 16 de novembro de 2017.
} 
agregadas. Em seus parâmetros quanto a intenção de otimizações nos processos produtivos, diz que, "[...] tanto do ponto de vista formal quanto técnico, podem ocorrer sempre que possível sem descaracterizar ou se afastar dos valores tradicionais e da história particular de cada núcleo artesanal" (2010, p. 33). Com o intuito de despertar discussões quanto ao comportamento da classe do design na sociedade, Landim questiona: "Por que ainda estamos formando designers como talentos criativos isolados no Planeta Design?" (2010, p. 14). Essa indagação, desperta em nós o interesse por respostas que apontem o caminho a ser traçado pelo design como ação de confronto ao seu isolamento social e profissional.

Com a mudança de perspectiva e uma nova realidade de consumo, o design colaborativo aparece com mais força. "As interações do design em uma organização transformam-se para torná-lo interativo e levam em consideração uma abordagem mais humana" (FONTANA, HEEMANN e FERREIRA, 2012, p. 372). Landim (2010) acrescenta ao dizer que o design infiltrado na periferia visa render-se de vez para o que possui de mais periférico, o que não é distante do que premedita os defensores do design social e da tecnologia intermediária, pois é na periferia que se concentra os maiores desafios para o setor.

\title{
2.1 Análise da qualidade de produtos artesanais
}

O design é uma área a qual tem como um de seus objetivos o estudo e análise de processo de projeto. Krippendorff (2000, p. 91) em suas palavras ainda tão atuais diz que, "o design gera um entendimento de segunda ordem da capacidade que os outros têm de projetar seus próprios mundos". A qualidade é o fator que mais importa na análise do produto, pois agrega valores positivos para o público ao qual está sendo projetado. Nesse sentido "o consumidor, ao adquirir produtos de forma consciente, desempenha papel fundamental na valorização e na preservação destas dimensões de qualidade" (KRUCKEN, 2009, p. 6).

\begin{abstract}
As contribuições do design para a valorização de produtos locais podem ser agrupadas em três linhas de trabalho: na promoção da qualidade dos produtos, dos territórios e dos processos de fabricação; no apoio a comunicação, aproximando o mercado e intensificando as relações territoriais; e no apoio ao desenvolvimento de arranjos produtivos e cadeias produtivas sustentáveis, as "cadeias de valor" (KRUCKEN apud GUIMARÃES E LUCCA, 2014, p. 6-7).
\end{abstract}

A qualidade nada mais é que "adequação ao uso", ela pode ser mensurada através da utilização de ferramentas durante o projeto, que são importantes para se chegar a fundo na real problematização, contribuindo assim, em sugestões de melhorias. Os profissionais da área são capazes de avaliar e aprimorar seus projetos com o uso das ferramentas atribuídas a gestão da qualidade e garantir a qualidade altera o conceito que o consumidor tem e até mesmo o fideliza em relação ao produto.

Para o consumidor de produtos artesanais, por exemplo, não é só o material empregado que influencia na hora da compra, nesta modalidade de compra, entra como quesito de qualidade, a história de concepção por trás do produto. $O$ artesanato que consegue cumprir esse papel, supre a dedução de qualidade de um ponto de visão mais específico, que chega mais próximo das referências do território e das questões de sustentabilidade. É a textura e forma que reflete o território e a cultura a qual foi concebido. Krucken sugere isso ao dizer que:

Não basta um produto ter alta qualidade; é preciso que seus atributos sejam percebidos de forma favorável. Ao escolher um produto, as pessoas buscam informações que possibilitem rastrear e identificar suas qualidades. $O$ design pode contribuir 
significativamente neste contexto, buscando formas para tornar visível à sociedade a história por trás dos produtos. (KRUCKEN, 2009, p. 9).

Pelo argumento da autora, entende-se que contar a "história do produto" significa comunicar elementos históricos, culturais e sociais, possibilitando ao consumidor avaliar e apreciar o produto de forma mais contextualizada, considerando, por exemplo, os serviços ambientais embutidos no próprio produto: "Ao escolher um objeto, as pessoas buscam informações que possibilitem rastrear e identificar suas qualidades" (KRUCKEN, 2009, p. 4).

$\mathrm{Na}$ concepção do que considerar valoroso a um produto, Moraes (2010, p. 11), ressalta uma observação ao dizer que "a própria qualidade e o entendimento do termo 'valor' vem regularmente redefinidos". Nesse sentido, "para atingir o resultado previsto, isto é, para produzir valor: mais que a tradicional 'cadeia de valor' ocorre hoje falar de 'rede de valor' ou de 'constelação de valor' [...]" (MANZINI apud DE MORAES, 2010, p. 11). Krucken (2009) elege para análise dois panoramas: a qualidade ampliada e a qualidade perceptível. Na ampliada, demosntrada na figura 1, destaca-se o território e as relações entre o produtor e usuários, e na qualidade perceptível, Krucken (idem) elege uma ferramenta para conceituação e aplicação, a estrela de valores, demonstrada na figura 2.

Figura 1 - A qualidade ampliada

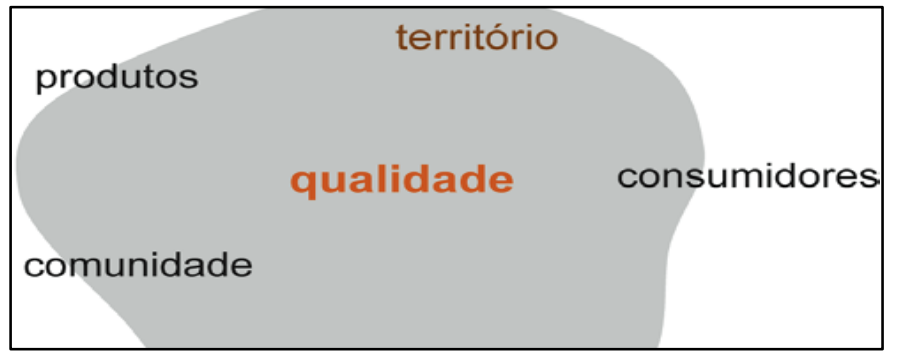

Fonte: Adaptado pelo autor a partir de Krucken (2009).

Segundo Krucken (Idem) a ferramenta possui, conforme a figura 2, seis vertentes norteadoras que auxiliam a visualização de um produto. As seis palavras que contam na estrela de valores são: Funcional; Ambiental; Econômico; Emocional; Social; Simbólico; Cultural.

Figura 2 - Estrela de Valores

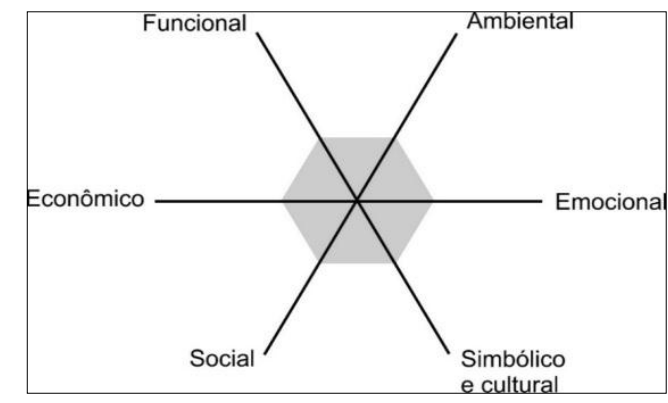

Fonte: Adaptada pelo autor a partir de Krucken (2009). 


\section{Artesanato: Renda e Crochê}

Compreende-se pelo ponto de vista observador, que o artesanato não é apenas uma manifestação cultural para quem o faz e para quem o compra, pela ótica de Paz apud Moura (2011, p. 32), "[...] o artesanato é uma espécie de festa do objeto: transforma o utensílio em signo de participação". Por ser algo tão empoderado, é necessário sabermos até onde vai a importância do artesanato e seus limites conceituais. Podemos tomar este conhecimento pelo o que a UNESCO compreende por produtos artesanais, a qual diz ser:

[...] aqueles confeccionados por artesãos, seja totalmente a mão, com o uso de ferramentas ou até mesmo por meios mecânicos, desde que a contribuição direta manual do artesão permaneça como o componente mais substancial do produto acabado. Essas peças são produzidas sem restrição em termos de quantidade com o uso de matériasprimas de recursos sustentáveis. A natureza especial dos produtos artesanais deriva de suas características distintas, que podem ser utilitárias, estéticas, artísticas, criativas, de caráter cultural, e simbólicas e significativas do ponto de vista social. (UNESCO apud BORGES, 2011, p.21)

Este conceito confirma o que, numa compreensão empírica, poderíamos definir sobre artesanato, sendo "o ato ou efeito do trabalho de modelagem de materiais com a mão, sem ou com a utilização de ferramenta". Todavia, o emprego da palavra "artesanato" em nosso contexto social, requer um significado mais expandido. No Brasil, o conceito estabelecido pelo MIDIC, agrega novos parâmetros ao que delimitasse ser artesanato dentro do país, como se pode observar logo abaixo.

O artesanato compreende a toda produção resultante da transformação de matériasprimas com predominância manual, por indivíduo que detenha o domínio integral de uma ou mais técnicas, aliando criatividade, habilidade e valor cultural (possui valor simbólico e identidade cultural), podendo no processo de sua atividade ocorrer o auxílio limitado de máquinas, ferramentas, artefatos e utensílios (MIDIC, 2012, p. 12).

Esses parâmetros que sugerem a obrigatoriedade de possuir um valor simbólico/identidade cultural, definido pelo MIDIC, parte do pressuposto de uma diversidade cultural existente no país, que possui dimensões continentais. Ter agregado ao artefato aspectos que sejam singulares, somam na tentativa de endereçar a sua origem e estabelecer a sua significância cultural. Nesse sentido, "um artesanato de qualidade deve ter uma clara identificação com sua origem, impressa nas cores, nas texturas, nas marcas deixadas pelas mãos dos artesãos em cada peça" (MASCÊNE, 2010, p. 37).

Para atingir esse reconhecimento de valor simbólico e de identidade cultural, o artesanato não dependerá apenas da técnica, mas da estética. É pela estética que se identifica a cultura a qual aquele produto se originou. De acordo com Paz apud Moura (2011, p. 32) "[...] há um contínuo vaivém entre utilidade e beleza; esse vaivém tem um nome: prazer. As coisas dão prazer porque são úteis e belas." O que desperta prazer ao se adquirir um objeto artesanal está intrinsicamente ligado ao belo, um jugo de valor estético.

É por seu atributo estético que o artesanato desperta interesse do design. O design que possui suas raízes no artesanato (como pôde ser observado no capítulo anterior) almeja intervir em todos os processos produtivos em que a estética é um fator determinante. 0 mérito estético do artesanato está intrinsicamente ligado ao material empregado. Segundo Mascêne (2010), as matérias-primas do artesanato, são retiradas da natureza, seja de origem mineral, vegetal ou 
animal, alteradas ou não artesanalmente/industrialmente ou por fruto da ocasião da reciclagem/reaproveitamento.

\subsection{A renda e a técnica do Crochê}

Segundo Ferreira (2001, p. 596) a renda consiste num "tecido delicado, de malhas abertas, cujos fios se entrelaçam formando desenhos". Essa definição sobre o que se trata ser renda sob um olhar mais amplo do termo, se dá, por haver uma variedade de técnicas, cujas características se aproximam e são atribuídas ao termo. Uma dessas, é o crochê, que pelo próprio autor (idem) se encaixa a referência definindo-se: "tecido rendado executado a mão com uma agulha que tem um gancho na extremidade" (FERREIRA, 2001, p. 195).

A palavra crochê tem origem no francês medieval, croké, termo que designava um instrumento de ferro recurvado, uma espécie de gancho, que permitia suspender ou segurar alguma coisa. No século XIX, surge na França à expressão broder au crochet (literalmente, "bordar com o gancho") (Borges apud Reis, 2016, p. 19).

Segundo Borges apud Reis (2016), não existe uma fonte concreta de onde e quando realmente surgiu o crochê. Reis confirma a hipótese, de que "tanto o crochê quanto o tricô, chegaram ao Brasil pelas mãos dos colonizadores portugueses e as subsequentes ondas migratórias de outros países europeus" (2016, p. 22). Segundo Braun (2013, p. 61) "durante o renascimento a técnica do crochê era um passatempo das classes sociais mais ricas, as mulheres uniam-se e produziam peças luxuosas que imitavam a renda Tambour, para ser utilizado com adornos de roupas ou decorações". Ao longo da história a medida em que as mulheres começaram a inserir-se no mercado de trabalho, Braun diz que "o crochê perdeu parcialmente seu espaço no âmbito feminino, já que as mulheres começaram a trabalhar e não sobrava mais tanto tempo para trabalhos manuais" (BRAUN, 2013, p. 64). Ainda assim, a técnica é sempre passada de geração para geração e não se torna obsoleta, pelo contrário, foi adquirindo o status de técnica delicada e fina.

No século XX entrou no auge através de grandes estilistas. Dior e Dolce Gabbana, grifes reconhecidas por ditarem sofisticação, já aplicaram a técnica em modelos de passarela, elevandoa ao conceito de requinte. Seguindo a contemporaneidade, o crochê está reconhecido e encontrase praticado em todo território nacional, através de suas diversas aplicações. Diante da evolução de atuação que o crochê vem adquirindo, a de maior relevância a esse projeto é a sua inserção em comunidades de baixa renda, como veículo de promoção social.

\section{Projeto Colaborativo}

Como foi explanado, o Design Social visa convergir o design a ser relevante para a solução de dilemas locais da sociedade a qual a profissão está inserida. A ação de executar o papel de facilitador dentre os envolvidos numa concepção projetual, através de um comportamento solidário, consisti em ser uma das principais evidências da manifestação dessa categoria.

Quando o foco é a construção de lugar em comunidades, o pensamento projetual é responsável por conceber, aplicar e otimizar dispositivos, recursos, técnicas e ferramentas que auxiliam na mudança de olhar da comunidade em relação a si e ao espaço que a circunda (SILVA, OLIVEIRA, et al., 2016, p. 2953).

O Espaço Mira Gabriel é o palco ideal para que o Design Social se deixe valer. É equivalente ao intuito de demonstrar o papel colaborativo da área, que o presente projeto não somente busca ser fiel ao campo do design, como também, ser sensível ao domínio técnico artesão 
desempenhado pelas envolvidas, estabelecendo uma troca de conhecimento através da aproximação.

O trabalho em sistema de parceria profissional entre o artesão e o designer, possibilita dar consistência ao Artesanato como elemento chave de perpetuação de manifestações culturais e delimitador de espaços geográficos e temporais nos locais de execução, a partir do registro de técnicas [...] servindo de veículo de divulgação de comunidades a um mercado exigente quanto às origens, meios e finalidades para que um produto seja consumido (PINTO, 2012, p. 50).

$\mathrm{O}$ que pode acontecer quando o design mergulha no artesanato é essa entrega a qual ressalta Pinto. A postura colaborativa do design com o crochê desempenhado no Espaço Mira Gabriel, possui antes de qualquer contato, uma intenção conceitual na materialização de uma proposta de aplicação da técnica sobre modo distinto do emprego habitual (confecção de tapetes) utilizado pelas crocheteiras, na expectativa de endereçar o artefato, agregando sentido e história para o mesmo. Por tanto, a proposta a ser efetivada será por definição conceitual. Ponderando ao que se define artesanato conceitual, Mascêne delimita como:

Objetos produzidos a partir de um projeto deliberado de afirmação de um estilo de vida ou afinidade cultural. A inovação é o elemento principal que distingue este artesanato das demais categorias. Por detrás desses produtos existe sempre uma proposta, uma afirmação sobre estilos de vida e de valores, muitas vezes explícitos por meio dos sistemas de promoção utilizados (MASCÊNE, 2010, p. 14).

O que se espera dessa proposta, não passa pela finalidade mercadológica, pois, por ser conceitual, visa ser norteador de trabalhos posteriores, os quais confirmarão a referência por meio de analogias ao produto conceito. Considerando-se isso, soma-se ao objetivo conceitual deste trabalho, a ótica de Tai, a qual indica que:

O conceitual refere-se à finalidade de expor ou manifestar ideias teóricas ou conceituais [...]. O conceitual the oferece um amplo espaço de ideias (das mais fantasiosas às mais prováveis soluções) para a manifestação de sua intenção e do seu potencial, que podem variar do nível idealista ao pragmático (TAI, 2017, p. 18).

\subsection{Percurso Metodológico}

Para o desencadeamento dessa proposta conceitual, o projeto seguiu por metodologia própria, tendo como induto, a metodologia de Jardim (2012). Algumas etapas da proposta original da autora foram mantidas, as demais retiradas e outras, acrescentadas. A autora, pela sua experiência em São Sebastião da Boa Vista na Ilha do Marajó, descreve que: "em conjunto com os artesãos resolvemos investir na busca de mercado, através de uma metodologia que valorizasse o produto, explorando o que de positivo foi diagnosticado do grupo" (JARDIM, 2012, p. 18). Há um grande proveito dessa frase pelo objetivo deste projeto, principalmente na palavra "conjunto". As etapas de concepção foram tomadas em unidade com os artesãos, com uma metodologia intencionada em valorizar o produto dos mesmos, retirando através de entrevista semiestrutura e de conversa informal, o mais positivo do trabalho executado no Espaço Mira Gabriel.

Os procedimentos tomados por Jardim e pelo grupo de artesãos por ela trabalhado consistem em três áreas atuantes: "Conscientização e motivação; criação e gestão" (JARDIM, 2012, p. 19). Por tanto, este projeto de proposta semelhante, interessa-se por essa alternativa metodológica, pela busca de adaptar o processo projetual à realidade local. Porém, as etapas receberam alterações e novas nomenclaturas para melhor evidenciar os significados de cada informação recolhida e repassada. 
A metodologia (ilustrada pela figura 3) se deu então da seguinte forma, primeiramente com um conhecimento prévio de trabalho acadêmico já realizado no campo de atuação, seguido pelo levantamento informacional do Espaço Mira Gabriel, onde o problema é percebido e abordado, o que leva ainda nessa etapa um estudo de mercado. No terceiro momento, surge a fase de criação da proposta, iniciada com uma conversa informal entre o grupo, realizando troca de conhecimento e de experiências, para que dessa descontração, o grupo possa executar a ferramenta mapa conceitual, que indicará a inspiração dos produtos a serem produzidos. Por fim, concebidos, terão um memorial descritivo da qualidade, validada pela ferramenta estrela de valor.

Figura 3 - Esquema da Metodologia

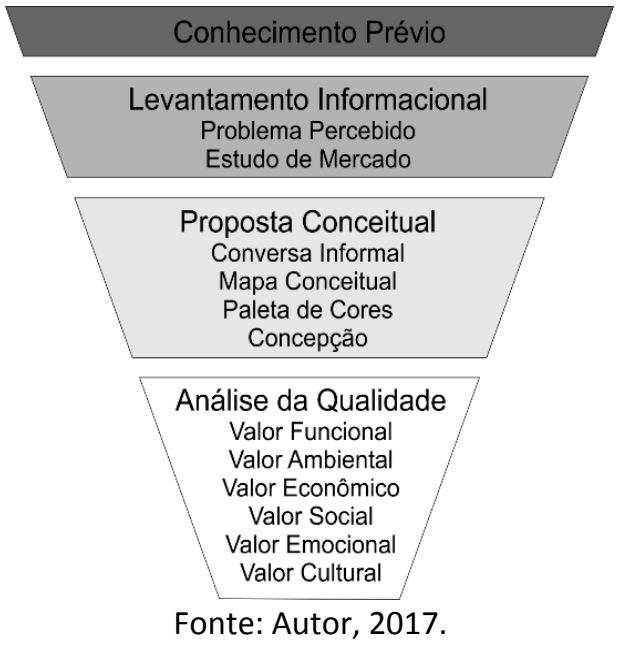

Não é a primeira vez que o Espaço Mira Gabriel, em especial o crochê ali trabalhado, relaciona-se com o design. Em 2014, acadêmicos do curso de Design da UEPA de Paragominas, desenvolveram alguns artefatos de vestuário, elaborados através de uma intervenção. Foi pela experiência desse primeiro plano, que o caminho para a efetuação de uma proposta mais expressiva começou a ser constituído.

Por essa segunda inserção do design, a intenção prática estava em guiar os trabalhos à um conceito, designando uma história por trás do produto e agregando valores de qualidade ao mesmo. A partir das entrevistas prévias em conjunto com o levantamento informacional sobre o Espaço Mira Gabriel, constatou-se que não somente o crochê desempenhado no local como também o curso de customização de sandálias com miçangas, não demonstrou aproveitamento no sentido mercadológico. Levantou-se então a hipótese de que o crochê que sofre do problema de uma única aplicação pudesse ser misturado na prática de customização de sandálias, servindo de alavanca para o resgate dessa prática e gerando retorno financeiro.

\subsection{Breve estudo sobre mercado e oportunidades}

Casar o crochê com a customização de sandálias não é uma prática muito inovadora no Brasil. Ao digitar no navegador da internet a frase "sandália de crochê", o pesquisador recebe acesso a uma infinidade de modelos e de vídeos tutoriais que ensinam como fazer. Esse fenômeno nos leva a uma compreensão empírica, de que o mercado para este tipo de produto está aberto. Entretanto, executando recortes geográficos, entendemos que este tipo de aplicação não é comum em todos os lugares, inclusive em Paragominas. Mas existem fatores externos e internos 
que contribuem na conclusão de que elaborar tal casamento entre crochê e customização de sandálias possui potencial e é economicamente viável, com base no que se lista logo a seguir:

- $\quad$ Público-Alvo

Na principal praça da cidade, acontece a feira de artesanato todos os fins de semana que atrai dezenas de consumidores que aderem ao produto.

- Concorrência

Em Paragominas a aplicação do crochê possui concorrentes diretos e indiretos. Dentre os concorrentes diretos, destaca-se a customização de sandálias feita com miçangas, que embora não tenha apresentado êxito no Espaço Mira Gabriel, possui um grande número de usuários na cidade e há artesãos que as faça.

\section{- $\quad$ Oportunidade de comercialização}

O Espaço Mira Gabriel já possui uma plataforma de vendas de tudo o que é produzido nele. A rede social de "Katarina Gabriel", sobrinha de Denise, responde pelo feito, ao exibir fotos dos produtos, vendidos por direct. Sites e redes sociais atualmente são plataformas de comercialização de alta relevância. Ter essa tecnologia já a disposição do Mira Gabriel é interessante para a fase de experimentação de demanda, efetuada com produtos posteriores aos conceituais elaborados por este projeto.

- $\quad$ Tendência ditada pela novela "A Força do Querer"

No Brasil, as novelas ditam moda. A trama do horário nobre das 21 horas, exibida pela Rede Globo no ano de 2017, teve a personagem da atriz Isis Valverde (Ritinha) como protagonista. A personagem que na estória é de origem paraense, contribuiu para que a novela revelasse o estado do Pará como tema, tanto pelo cenário, culinária e lendas, quanto pelos costumes populares e vestuário característico desse Estado. O sucesso da novela foi eminente e sua menção ao Pará perdurou e demonstrou grande eficácia. O crochê esteve presente em quase todas as cenas no vestuário utilizado pela protagonista na trama. O site gshow, faz referência o estilo de Ritinha como ribeirinho. Ao descrever um dos looks, o site diz: "a peça com estampa floral ganha um ar mais brejeiro ainda com o crochê que cobre o colo do vestido" (ROCHA/ GSHOW, 2017). Já o site vestimentarte comenta: "Eu entendo que o figurino da Ritinha busca representar o estilo de uma moça de origem humilde do interior do Pará" (MELO/ VESTIMENTARTE, 2017).

\section{Coleção Mira na Metamorfose}

O primeiro contato deste atual projeto com as artesãs do Espaço aconteceu no dia 06 de outubro de 2017, onde ocorreu uma conversa informal com as mulheres presentes. Durante a conversa, todas foram ouvidas, cada uma, em sua oportunidade, descreveu a importância do artesanato para si. Esse diálogo informal trouxe a luz em alguns momentos, sentimentos afetivos das mulheres para com o Espaço. Em uma das falas, pelo ponto de vista pessoal, foi apontado que a entidade se tornou a responsável no processo de reversão do quadro de depressão. As demais artesãs presentes, também se identificaram com o enunciado. Foi um momento em que os sentimentos se afloraram, o que confirma a hipótese de que o artesanato, não é visto apenas como demonstrativo cultural para quem o faz, mas como uma ocupação prazerosa, que une o funcional e o belo.

$\mathrm{Na}$ oportunidade, o design foi apresentado como figura colaborativa ao desempenho do 
crochê executado por elas. Foi um ponto enaltecido perante as mulheres, a ligação histórica entre as áreas como uma das justificativas para a aproximação mais igualitária entre os ofícios.

Nesse estágio, não consistia em estabelecer limites de cada função, mas de levantar um acervo de significações. Conforme o que diz Zanella, Balbinot e Pereira, "as significações, são resultantes das trocas entre diferentes sujeitos em contextos específicos, sendo marcadas tanto pelas histórias de cada um quanto do contexto e do grupo social a qual pertencem" (ZANELLA, BALBINOT e PEREIRA, 2008, p. 170). Para Jones (JONES, 2011, p. 215), "do ponto de vista criativo, pode ser útil 'colocar-se na pele de outra pessoa' [...]".

\subsection{Mapa Conceitual}

De forma integrada, o grupo utilizou-se da ferramenta mapa conceitual, que segundo Tavares (2007, p. 72), "é uma estrutura esquemática para representar um conjunto de conceitos imersos numa rede de proposições". Essa ferramenta possui variados modelos de execução, dentre eles encontra-se o mapa conceitual do tipo teia de aranha, a qual Tavares (Idem) detalha: "ele é organizado colocando-se o conceito central (ou gerador) no meio do mapa. Os demais conceitos vão se irradiando na medida em que nos afastamos do centro". Tendo optado pelo modelo acima mencionado, foram então elaborados quatro mapas, no intuito de contemplar quatro recortes geográficos (Amazônia, Pará, Paragominas e Parque Ambiental), afim de escolher um como definição territorial, sendo o primeiro o escolhido por possuir o que nos serviria de inspiração.

- Mapa Conceitual da Amazônia: Nesse primeiro mapa, catalogaram-se junto as artesãs, as principais referências da Amazônia. Durante o processo as artesãs foram instigadas a descreverem o que vem primeiro a mente quando ouvido esse que nos serve aqui de "conceito central". Diante do desafio, entraram para o orbe desse mapa as palavras: verde, rios, riqueza, floresta, plantas, desmatamento, remédio, água, animais, borboletas, boto, macaco, quati. A aplicação prática da ferramenta pode ser observada pela figura 4.

Figura 4 - Mapa Conceitual - Amazônia

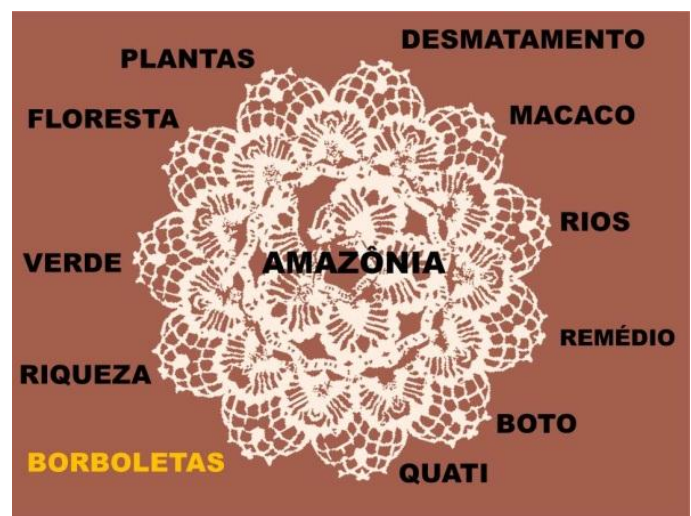

Fonte: Autor, 2017.

- Mapa Conceitual do Pará: Desafiadas agora a conceituarem o Pará, as crocheteiras não demoraram em liberar as palavras, e formando o mapa conceitual desse, encontram-se as palavras: açaí, vermelho, Joelma Círio, brega, Ritinha, tacacá, maniçoba, Paysandu, Ver-o-Peso, Dona Onete. 
- Mapa Conceitual de Paragominas: no recorte geográfico local, as crocheteiras citaram como conceitos: Município Verde, Adnan, Denise, Célio Miranda, calor, limpeza, Lago Verde, soja, caro, bauxita.

- Mapa Conceitual do Parque Ambiental: Na quarta tentativa de mapa conceitual, o grupo estabeleceu: Fernando, arara, quati, trilha, pedalinhos, memorial, Saci, Tamarindo, Pirarucu.

Segundo Overal e Silva (2008, p. 1) "as borboletas fazem parte do nosso cenário amazônico, atraindo-nos pela beleza multifacetada de seus desenhos e pelo multicolorido de suas asas". Sabedores dessa condição, o grupo optou por esse animal citado no mapa conceitual da Amazônia. Ainda retratando sobre, Overal e Silva (Idem) dizem que, "as borboletas e mariposas passam por quatro fases durante sua vida: ovo, lagarta, crisália e adulto. Esta surpreendente mudança é chamada de metamorfose". Esse fenômeno "metamorfose" a qual essa espécie atravessa, deixando de rastejar-se como lagarta e passando a alçar novos voos, possui ligação com esse grupo de mulheres.

Mediante a todas as informações absorvidas, a coleção por elas executadas tem as borboletas da Amazônia como inspiração. Possui como missão, referenciar não só apenas o próprio território amazônico, como também de representar essas mulheres, que encontraram no crochê uma forma de sair de um estado depressivo para um papel atuante e digno na sociedade.

No decorrer da semana de colaboração do design, o grupo teve acesso ao livro "Borboletas da Amazônia" do museu Emílio Goeldi desenvolvido por Overal e Martins, onde diversas borboletas e mariposas da região são listadas. Sites que listam outras ausentes no documento, foram itens de pesquisa. A escolha das borboletas e mariposas selecionadas para inspirarem esta coleção, foi guiada por dois fatores: peculiaridade comportamental da borboleta e cores compatíveis à disponibilidade de linhas no Espaço Mira Gabriel e no mercado do bairro. Tendo por fim, discutidas as borboletas, foram definidas, três espécies, que por seus nomes científicos são: Hamadryas, Phoebis Philea e Rothdchildia sp.

\subsection{Produtos da Coleção}

Para abrir essa coleção, um verso foi elaborado no objetivo de preparar os olhos para o conceito exposto. Tal verso pode ser lido na figura 5 , logo abaixo.

Figura 5 - Verso

\section{Sou Mira e peço que mire em mim.}

Sou linda, sou feia, não me importa como irás me definir.

Eu sei de onde sair e sei pra onde eu vou.

Se prepara que agora tô levantando meu voo.

Amazônia é brega, Amazônia eu crocheto.

Amazônia é minha terra, Amazônia é o chão que piso.

Piso na depressão, piso com minha imaginação.

É pisando que vem chegando a minha coleção.

Fonte: Autor, 2017. 
Rasteirinha "Asas da noite": Com adereços translúcidos, nítidos na figura 6, essa sandália busca inspirar-se na mariposa Olhos da Noite, onde a característica translúcida das asas se encontram presentes como detalhe mais característico. Para conseguir chegar a esse efeito, foi utilizado recortes de garrafa pet.

Figura 6 - Rasteirinha Asas da Noite

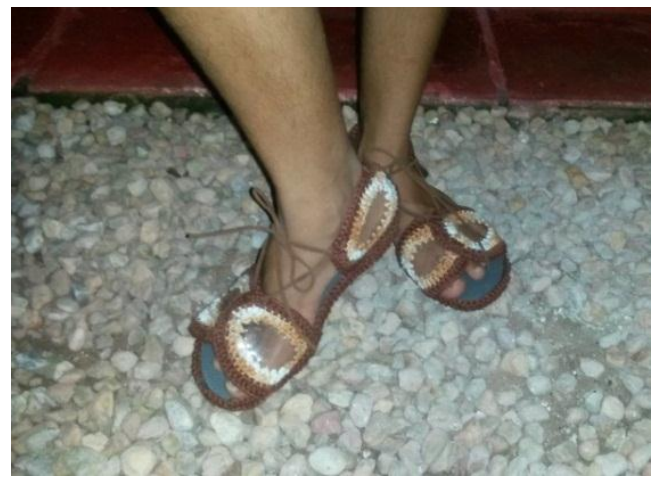

Fonte: Autor, 2017

Gladiadora "Voo e faço barulho": Essa sandália foi pensada para demonstrar hábitos da borboleta estaleiro, que em seu repouso não mantem as asas fechadas e emite barulhos para chamar atenção do sexo oposto. Conforme o que se observa na figura 7, o pé até a canela é envolvido por tiras verdes, visando representar um galho onde a estaleiro resolveu pousar.

Figura 7 - Voo e chamo a atenção

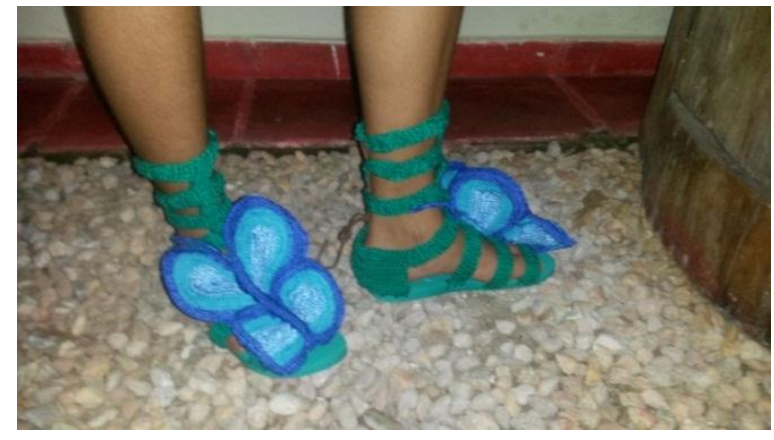

Fonte: Autor, 2017.

Sapatilha "Panapaná": Demonstrada na figura 8, essa sapatilha representa esse fenômeno típico na região. Segundo Overal e Silva $(2008$, p. 7), "grandes migrações de borboletas são comuns na Amazônia, quando nuvens de milhares ou até milhões de borboletas pintam os céus com suas cores amarelas [...]". 
Figura 8 - Sapatilha Panapaná

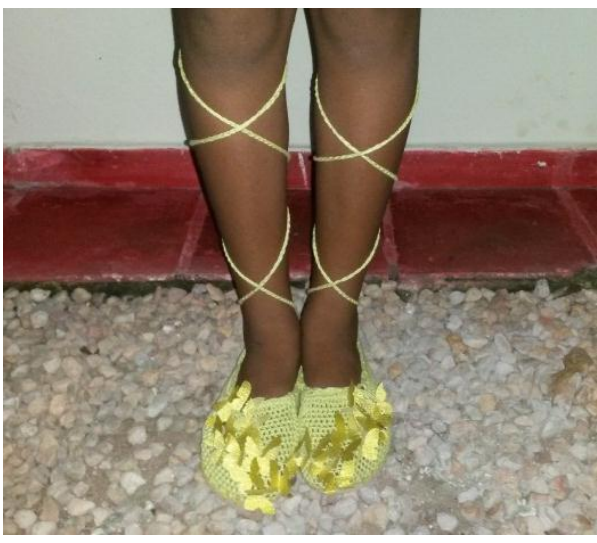

Fonte: Autor, 2017

\subsection{Memorial Descritivo}

A ferramenta Estrela de Valores se faz presente nessa etapa de análise da qualidade de produtos artesanais de enfoque territorial. Vale ressaltar que a estrela de valores é uma análise avaliativa realizada para ilustrar a qualidade percebida ou percepção de qualidade, efetuada com base na observação e não na experimentação, o que conciliar-se bem aos produtos de uma coleção conceitual, onde os produtos não são disponíveis para tato e testes físicos. Tendo este trabalho como modelo, a avaliação funciona da seguinte forma: inicia-se o julgamento de fora para dentro, onde as características do produto são listadas, relacionadas e posicionadas frente à um dos raios que emana do centro. Esses raios, pela visão de Lia Krucken (2009), são valores básicos em um produto de design de territorial, neste caso, tendo como núcleo a coleção. Neste caso, esse memorial descritivo não requer pesquisa à campo, pois o olhar do cliente já está traduzido pelos valores (Emocional, Ambiental, Funcional, Social, Econômico e Cultural) listados por Lia Krucken (Idem), permitindo ao grupo a ação de encaixar as características a eles, conforme ilustrado pela figura 9 logo a baixo:

Figura 9 - Estrela de Valores da Coleção Mira na Metamorfose

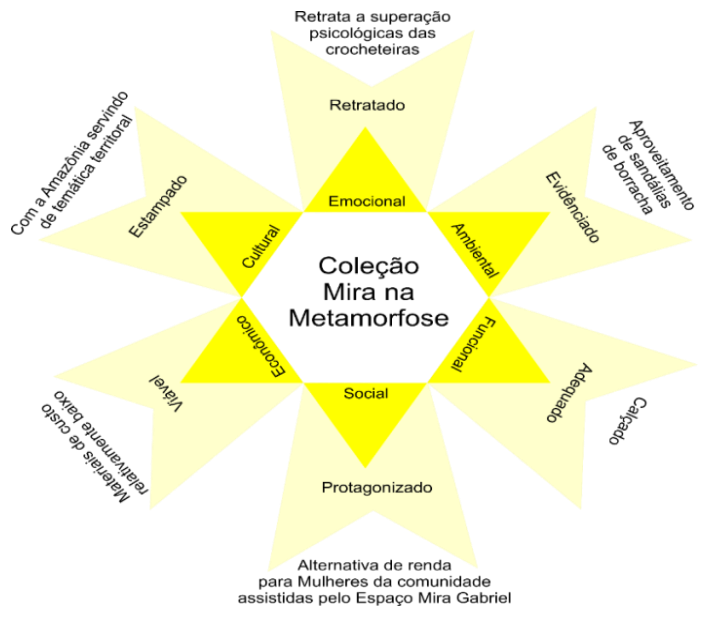

Fonte: Autor, 2017. 
Mais que apenas ter um vislumbre dessa qualidade percebida por um futuro cliente, este trabalho interessa-se pela avaliação do conjunto de crocheteiras quanto a esta colaboração do design no processo. No ultimo contato realizado no dia 05 de dezembro de 2017, as crocheteiras em uma só voz, elevaram a positividade dessa relação, ressaltando que: "cada peça não representa apenas o que sabem fazer ou o que aprenderam. Mais profundo que isso, representa o que somos". O design ajudou às mulheres do Mira Gabriel a se enxergarem em seus próprios produtos.

\section{Considerações Finais}

Pelo estudo, observou-se que a ligação do design com o artesanato não surgiu recentemente, mas desde suas origens. O resgate dessa relação, agora de maneira recíproca por parte do design, é um dos caminhos encontrados pela categoria como forma de prestar seu papel social. Esse papel, referido por Design Social, desenvolve projetos junto à comunidade numa relação transdisciplinar, onde o efeito consiste na troca de conhecimentos entre design e as áreas envolvidas na concepção projetual. Envolvendo-se com o artesanato, o Design Social entra no papel de facilitar a busca por referências e por suas ferramentas projetuais garantir a qualidade do produto. Servindo este projeto como demonstrativo do trabalho.

O problema enfrentado pelas artesãs assistidas pelo Espaço Mira Gabriel, chegou a ser solucionado com a concepção de uma coleção conceitual elaborada em conjunto. A coleção de calçados enaltece o território amazônico através da inspiração de um animal da própria fauna, serve de demonstrativo positivo de que o design pode inserir-se nos setores mais complexos de produção, quanto nos mais básicos, e ainda sim, ser considerado design.

O calçado usa como material solados de sandálias de borracha que podem ser compradas em qualquer comércio por um preço acessível e o barbante de lã que pode ser adquirido em qualquer armarinho, resultando em um trabalho de redesign, que sugere inserir o crochê num mercado de sandálias customizadas na cidade. Os benefícios do design em sua visão social através deste ensaio, não pesam mais para o lado artesão que para o designer. O designer possui através dessa ação, a oportunidade de se aproximar veemente da comunidade e ser reconhecido pelo seu trabalho num contexto social.

Por outro lado, no esforço de ser fiel à definição conceitual estabelecida no coletivo, o trabalho indicou dificuldades quanto à catalogação das borboletas que povoam a Amazônia. Outra grande dificuldade encontrada foi à disponibilidade de tempo para elaborar o crochê das peças. Muitos adereços e acabamentos tiveram de ser otimizados e em alguns casos descartados para que fossem revelados os produtos feitos neste documento.

Fica como futuras possibilidades de trabalhos a ampliação das propostas de atuação do design dentro da comunidade local, valorizando o saber-fazer como uma característica de um design amazônico, podendo explorar as demais palavras que aparecem nos mapas conceituais, por exemplo, colaborando na construção de uma sociedade que valoriza o ambiente cultural próprio, como um modo de se opor a uma industrialização nociva e destrutiva ao conhecimento tradicional. Outra etapa que essa colaboração visa se elevar é para a concepção de produtos comerciais, onde uma pesquisa de mercado mais aprofundada será realizada para guiar-nos a um trabalho que receba aprovação com base na qualidade experimentada. 


\section{Referências}

AMORIM, L. F. Design (para o) Social. Site Designers Brasileiros, 2017. Disponivel em: <https://designersbrasileiros/design-social>. Acesso em: 21 Outubro 2017.

BARROS, L. A. D. S.; MAGALHÃES, F. D. Um voo em parceria: articulação design, academia e setor público no Rio de Janeiro. 12 Congresso Brasileiro de Pesquisa e Desenvolvimento em Design , Belo Horizonte, 9, n. 2, Outubro 2016. 4604-4614. Disponivel em: <www.procedings.blucher.com.br>. Acesso em: 6 Junho 2017.

BORGES, A. Design + Artesanato: o caminho brasileiro. São Paulo: Terceiro Nome, 2011.

BRASIL, C. D. D. Projeto de Lei no 1965, de 28 de maio de 1996. Conceitos do Design - Projeto de Lei que visa regularizar a profissão de designer no Brasil, 1996. Disponivel em: <http://www.camara.gov.br/proposicoesWeb/fichadetramitacao?idProposicao $=198210>$. Acesso em: 16 Junho 2017.

BRAUN, S. M. A. H. Intervenção urbana com fios: o tricô e o crochê na arte contemporânea em uma perspectiva educativa. Porto Alegre: UFRGS, 2013.

CARDOSO, R. Uma introdução à história do design. 3ạ. ed. São Paulo: Blucher, v. IV, 2008.

DE MORAES, D. Metaprojeto: o design do design. São Paulo: Blucher, 2010.

FARINA, M.; PEREZ, C.; BASTOS, D. Psicodinâmica das Cores em Comunicação. 6ạ ed. São Paulo, 2011.

FERNANDES, W. A. Movimentos da Qualidade no Brasil. Brasil: Inmetro, 2011.

FERREIRA, A. B. D. H. Miniaurélio Século XXI Escolar: O minidicionário da língua portuguesa. 4ạ. ed. Rio de Janeiro: Nova Fronteira, 2001.

FONTANA, I. M.; HEEMANN, A.; FERREIRA, M. G. G. Design Colaborativo: Fatores Críticos para o Sucesso do Codesign. 4 Congresso Sul Americano de Design de Interação, São Paulo, Abril 2012. 371-382.

GIL, A. C. Métodos e Técnicas de Pesquisa Social. 6a. ed. São Paulo: Atlas, 2008.

GOMES, D. D.; ARAÚJO, K. M. D. Linha do Tempo das Políticas de Design: Das grandes exposições às políticas internacionais integradas. 12 Congresso Brasileiro de Pesquisa e Desenvolvimento em Design, Belo Horizonte, outubro 2016. 268-278. Disponivel em: <http://www.proceedings.blucher.com.br>. Acesso em: 06 Setembro 2017.

GUIMARÃES, M. J. S.; DE SOUZA, A. L. Valorização do Território: uma via para o design sustentável no Maranhão. 11ㅇ Congresso Brasileiro de Pesquisa e Desenvolvimento em Design, Gramado, 
2014. 1-9. Disponivel em: <http://www.proceedings.blucher.com.br/article-details/valorizao-doterritrio-uma-via-para-odesign-sustentvel-no-maranho-12795>. Acesso em: 20 set. 2017.

JARDIM, N. R. T. Design e Artesanato: relatos de uma experiência em São Sebastião da Boa Vista, Ilha do Marajó/Pará/Brasil. In: FREITAS, A. P. N. D., et al. Cultura e Design em Produtos Amazônicos. Belém: Cromos, 2012. p. 16-24.

JONES, S. J. Fashion Design: manual do estilista. São Paulo: Cosac Naify, 2011.

KAZAZIAN, T. Haverá a idade das coisas leves: design e desenvolvimento sustentável. São Paulo: Senac São Paulo, 2005.

KELLER, L. P. D. M.; CAMPOS, L. D. O Design e a Técnica: Transformando fatos incontestáveis em questões de ponderação. 12 Congresso Brasileiro de Pesquisa e Desenvolvimento em Design, Belo Horizonte, Outubro 2016. 170-181. Disponivel em: <http://www.proceedings.blucher.com.br>. Acesso em: 06 Setembro 2017.

KRIPPENDORFF, K. Design centrado no ser humano: uma necessidade cultural. In: MEIRELES, G. Estudos em Design. Rio de Janeiro: Associação de Ensino de Design do Brasil, v. VIII, 2000. Cap. 3, p. 87-98.

KRUCKEN, L. Design e Território: uma abordagem integrada para valorizar identidades e produtos. 2o Simpósio Brasileiro de Design Sustentável, São Paulo, 2009. 1-10. Disponivel em: <http://www.anhembi.com.br/sbds>. Acesso em: 20 set. 2017.

LANDIM, D. C. Design, empresa, sociedade. 1a. ed. São Paulo: Cultura Acadêmica, v. I, 2010.

LÖBACH, B. Design industrial: bases para a configuração dos produtos industriais. São Paulo: Edgard Blücher, 2006.

MALDONADO, T. Design industrial. Lisboa: Edições 70, 1991.

MASCÊNE, D. C. Termo de referência: atuação do Sistema SEBRAE no artesanato. Brasília: SEBRAE, 2010.

MELO, M. M. D. E. A. Artesanato e design: fluxos e hibridações na cultura brasileira. In: SOCIAL, G. E. C. Trabalho de Conclusão de Curso. Belo Horizonte: Pontifícia Universidade Católica de Minas Gerais, 2002. p. 92.

MELO, T. O Crochê no figurino de Ritinha (Ísis Valverde) em a Força do Querer. Vestimentarte, 2017. Disponivel em: <www.vestimentarte.com.br/2017/07/figurino-isis-valverde-forca-querer.html?m=1>. Acesso em: 21 Outubro 2017.

MIDIC, M. D. D. I. E. C. E. Programa de Artesanato Brasileiro. Brasília: [s.n.], 2012. Disponivel em: <http://www.desenvolvimento.gov.br/arquivos/dwnl_1347644592.pdf>. Acesso em: 15 out. 2017.

MORAES, D. D. Análise do design brasileiro: entre mimese e mestiçagem. São Paulo: Edgard Blücher, 2006. 
MOURA, A. N. D. A influência da cultura, da arte e do artesanato brasileiro contemporâneo: um estudo da obra dos irmãos Campana. Belo Horizonte: UEMG, 2011. Acesso em: 22 Junho 2017.

MOURÃO, N. M.; ENGLER, R. D. C. Economia Solidária e Design Social: iniciativas sustentáveis com resíduos vegetais para produção artesanal. INTERAÇõES, Campo Grande, v. 15, n. 2ª , p. 329-339, Dezembro 2014.

OVERAL, L. W.; SILVA, P. J. B. Borboletas da Amazônia. Belém: Museu Paraense Emílio Goeldi, [s.d].

PAPANEK, V. Design for the real world: Human Ecology and Social Change. Londres: Thamesand Hudson, 2000.

PINTO, R. G. O Artesanato de Referência Cultural da Colônia de Chicano no município de Santa Barbara no Pará como indicador e delimitador territorial. In: FREITAS, A. P. N. D., et al. Cultura e Design em Produtos Amazônicos. Belém: Cromos, 2012. p. 44-55.

POYNOR, R. Abaixo as regras. Porto Alegre: Bookman, 2010.

REIS, C. A Valorização do Artesanato na Moda em Vestidos de Festa. Juiz de Fora: Universidade Federal de Juis de Fora, Instito de Artes e Design, 2016.

RICETTI, Tereza Maria; MARTINS, Nara Silva Marcondes; OGASAWARA, Luís Alexandre f. Design, Ponto de Vista e Perspectivas: sobre a cultura do projeto, educação e atuação profissional. 12을 Congresso Brasileiro de Pesquisa e Desenvolvimento em Design. Belo Horizonte, n. 2, v. 9, Outubro 2016. 2559-2569. Disponivel em: <http://www.proceedings.blucher.com.br>. Acesso em: 06 Setembro 2017.

RIEGEL, S.; ZUCHETTI, D. T. Design de Produtos e o Artesanato. Conhecimento Online, v. I, 2011.

ROCHA, F. Dicas de moda: vestido colorido de Rita faz sucesso no capítulo de 14/6, de 'A força do Querer'. Gshow, 2017. Disponivel em: <https://gshow.globo.com/Estilo/noticia/dica>. Acesso em: 6 Novembro 2017.

SANTANA, M. F. Design e Artesanato: Fragilidade de uma aproximação. Cadernos Gestão Social, Salvador, v. III, n. 2, p. 103-115, Dezembro 2012.

SCHNEIDER, B. Design - uma introdução: o design no contexto social, cultural e econômico. São Paulo: Blucher, 2010.

SEBRAE, S. B. D. A. À. M. E. P. E. Design para todas as empresas. Brasília: [s.n.], 2012.

SILVA, A. L. D. S. V. et al. Disposítivos Estratégicos de Design Social em Processos de Construção de Identidade Local. 12 Congresso Brasileiro de Pesquisa e Desenvolvimento em Design. Belo Horizonte, n. 2, Outubro 2016. 2950-2961. Disponivel em: <http://www.proceedings.blucher.com.br>. Acesso em: 06 Setembro 2017.

SILVA, J. C. R. P. D. et al. O Futuro do Design no Brasil. 1ạ. ed. São Paulo: Cultura Acadêmica, 2012. 
STAUDT, D. Projeto Design Social: valorização de produtos artesanais com enfoque no turismo local, 2012.

TAl, H.-A. Design: conceitos e métodos. São Paulo: Blucher, 2017.

TAVARES, R. Construindo Mapas Conceituais. Ciências \& Cognição. João Pessoa, v. 12, Dezembro de 2007. 72-85. Disponível em: < http://www.cienciasecognicao.org/>

VASQUES, R. A. Design, posse e uso compartilhado: reflexões e práticas. São Paulo: FAUUSP, 2015.

ZANELLA, A.; BALBINOT, G.; PEREIRA, R. Tu me ensina a fazer renda que eu te ensino a. inovar: um estudo do processo de constituir-se rendeira à luz da psicologia histórico-cultural. Cidadania e participação social [online], Rio de Janeiro, p. 168-179, 2008. ISSN 978-85-99662-88-5. Disponivel em: <http://books.scielo.org>. Acesso em: 4 out. 2017.

WANDERLEY, Marcela L'Amour; ANDRADE, Pollyanna Sitônio; BARROS, Rafaela Queiroz de; JÚNIOR, William Guedes Lins. Bases Comuns do Design: uma discussão sobre o impacto e papel social do design. In: ARRUDA, Amilton J. V. Design \& Complexidade [livro eletrônico]. São Paulo : Blucher, 2017. p. 10-22. Disponível em: <http://pdf.blucher.com.br.s3-sa-east-1.amazonaws.com /openaccess/9788580392159/completo.pdf>. Acesso em: 05 de dezembro de 2017. 